\title{
A Practical Approach to Hypertension Management in Diabetes
}

\author{
Altamash Shaikh
}

Received: May 2, 2017 / Published online: September 19, 2017

(C) The Author(s) 2017. This article is an open access publication

\begin{abstract}
Hypertension is one of the most important comorbidities of diabetes, contributing significantly to death and disability and leads to macrovascular and microvascular complications. When assessing the medical priorities for patients with diabetes, treating hypertension should be a primary consideration. Practical approaches to hypertension in diabetes, including individualized targets are discussed, as per stage and complication of diabetes, according to current studies and guidelines. Angiotensin converting enzyme inhibitors (ACEI)/angiotensin receptor blockers (ARBs) are the most effective drugs for treating hypertension in diabetes, in the absence of contraindications. Calcium antagonists or diuretics are acceptable as second-line agents. Once the target is achieved, antihypertensive drugs should be continued. Newer antidiabetes medications such as sodium glucose cotransporter- 2 inhibitors (SGLT2i), glucagon-like peptide-1 receptor agonists (GLP1-RA), and dipeptidyl peptidase- 4 inhibitors (DPP4i) have antihypertensive
\end{abstract}

Enhanced content To view enhanced content for this article go to http://www.medengine.com/Redeem/ 423CF0603B07DC9F.

\section{A. Shaikh $(\bowtie)$}

Department of Endocrinology, Saifee Hospital,

Mumbai, India

e-mail: ealtamash@gmail.com properties and may assist in treatment decision-making.

Keywords: Antidiabetic; Antihypertensive; Azilsartan; Diabetes, DPP4; GLP1Ra; Hypertension; Macrovascular; Microvascular; SGLT2

\section{INTRODUCTION}

Hypertension is one of the most important comorbidities of diabetes [1, 2], contributing significantly to death and disability [3]. It is responsible for macrovascular (atherosclerotic cardiovascular disease, peripheral arterial disease, stroke) and microvascular (retinopathy, neuropathy, nephropathy) complications [4]. Although we have an array of antihypertensive drugs, recently newer blood pressure-lowering drugs and antidiabetic drugs with antihypertensive properties have become available. Several trials [5-7] have shown the significance of managing hypertension in diabetes; thus, treating hypertension is an important part of cardiovascular (CV) risk reduction. This article aims to present a practical approach to hypertension in diabetes. This article is based on previously conducted studies and does not involve any new studies of human or animal subjects performed by the author. 


\section{EPIDEMIOLOGY}

Hypertension is twice as common in patients with diabetes than in patients without diabetes [8]. Hypertension (defined as at least $140 / 90 \mathrm{mmHg}$ or on therapy for hypertension) in an overweight or obese asymptomatic person is also one of the criteria to test for diabetes or prediabetes, and is thus, an important risk factor for diabetes [4]. Individuals aged 55 years or older have a $90 \%$ chance of developing hypertension, and approximately $70 \%$ of patients with diabetes over the age of 40 years also have hypertension [9]. Eight out of ten diabetes patients are affected by CV-related issues, leading to death [10]. Hence, treating hypertension in diabetes should be a primary consideration when assessing the medical priorities of patients with diabetes.

\section{PATHOPHYSIOLOGY}

The pathophysiology of hypertension and diabetes is interrelated, complex, and poorly understood [3]. Various mechanisms are involved including overactivity of the sympathetic nervous system, renin-angiotensin-aldosterone system (RAAS) activation, abnormal renal sodium handling, endothelial dysfunction, damage to arteries (small and large), impairment of insulin-mediated vasodilatation, abnormal immune responses, and inflammation [11]. Hypertension and diabetes are both low-grade chronic inflammatory diseases. Insulin resistance is key as it is a prothrombotic state, caused by increased production of inflammatory cytokines like tumor necrosis factor alpha (TNF- $\alpha$ ), interleukin-6 (IL-6), etc., and this along with the increase in plasminogen activator inhibitor-1 (PAI-1) and fibrinogen leads to CV events [12].

Obesity is a common risk factor for both diabetes and hypertension. Obesity and diabetes have common genetic factors that have a strong additive effect in the development of hypertension [4]. The greater the number of hypertension genes, the greater the risk of hypertension. Stress, also links diabetes and hypertension, as a known CV risk factor [2].
Thus, genetic factors and environmental factors (diet, exercise), which form the basis of the "common soil" hypothesis, lead to diabetes and atherosclerosis. These mechanisms may combine to form a vicious cycle of hypertension and diabetes. Both are the end results of metabolic syndrome.

\section{MANAGEMENT}

\section{Assessment}

Measuring blood pressure (BP) is one of the most important aspect of the clinical examination of a diabetes patient. The patient should be seated with a backrest, their feet resting on the ground, and their arm resting or supported at heart level. BP measurement should be taken with an appropriate cuff size, after 5 min of rest, taking 2-3 readings while the patient is quiet. The cuff should be next to skin, sleeve not rolled up and checked at each patient visit by a trained health care professional. Measuring BP in supine, sitting and standing positions, also enables the exclusion of possible autonomic neuropathy $[4,13]$.

\section{Targets and Implications}

Lowering of BP is beneficial in many ways. The UKPDS trial showed that reducing BP from $160 / 94$ to $144 / 82$ reduced diabetes-related mortality (BP was 154/87 in another arm of the study) [4]. The reduced morbidity from heart failure $(56 \%)$ and reduced mortality from macrovascular complications (34\%), as evidenced in UKPDS [5], and benefit of BP reduction in diabetes were also seen in SHEP, ALLHAT, ASCOT, and HOT trials [6, 14-16].

A multifactorial approach towards the control of hypertension and hyperglycemia reduces both macro- and microvascular complications as seen in various trials (UKPDS [5], ADVANCE [7], STENO-2 [17]). Treatment of hypertension in diabetes must be individualized, depending on comorbidity, advancing age, and advancing diabetes. Treatment should begin when BP is greater than $140 / 90[4,18]$. Certain subsets of 
hypertension in diabetes, with proteinuria and diabetic kidney disease, may benefit from further lower targets. Control of BP also significantly reduces microalbuminuria and reduces new or worsening nephropathy [7] and, thus, impacts microvascular complication. In the elderly (over 80 years old) $[19,20]$, a BP target of 150/90 seems appropriate (Table 1 ).

Treatment of hypertension, whether uncomplicated or complicated, with presence of albuminuria and advancing age must be tailored to real-world requirements. For albuminuria patients, targets may be stricter. Masked hypertension is also quite common in type 2 diabetes mellitus (T2DM). Resistant hypertension may also be present in diabetes $[4,28]$. The achievement of the individualized BP goal

Table 1 Summary of the various targets given by different societies for the management of hypertension in diabetes

\begin{tabular}{lll}
\hline Guideline/society & $\begin{array}{l}\text { Target } \\
(\mathbf{m m H g})\end{array}$ & $\begin{array}{l}\text { First drug class } \\
\text { recommendation }\end{array}$ \\
\hline UK NICE [18] $]^{\mathrm{a}}$ & $130 / 80$ & ACEI/ARB \\
CHEP [21] & $130 / 80$ & ACEI/ARB \\
WHO [22] & $130 / 80$ & ACEI/ARB \\
IDF [23] & $130 / 80$ & ACEI/ARB \\
JSH [24] & $130 / 80$ & ACEI/ARB \\
IGH [25] & $140 / 80$ & ACEI/ARB \\
ESC/ESH [19] & $140 / 85$ & ACEI/ARB \\
ADA [4] ${ }^{c}$ & $140 / 90$ & ACEI/ARB \\
JNC-8P [20] & $140 / 90$ & ACEI/ARB \\
ASH/ISH [26, 27] & $140 / 90$ & ACEI/ARB \\
AHA/ACC/ASH [26] & $140 / 90$ & ACEI/ARB \\
\hline
\end{tabular}

$A C E I$ angiotensin converting enzyme inhibitor, $A R B$ angiotensin receptor blocker

a Begin treatment if $\mathrm{BP}>140 / 90 \mathrm{mmHg}$

b $<140 / 90 \mathrm{mmHg}$ in patients $70-80$ years old, $<150 /$ $90 \mathrm{mmHg}$ in patients over 80 years old

c Systolic BP (SBP) $<130 \mathrm{mmHg}$ and diastolic BP (DBP) $<80 \mathrm{mmHg}$ may be appropriate for certain individuals with diabetes, such as younger patients, those with albuminuria, and/or those with hypertension and one or more additional atherosclerotic CV disease risk factors if they can be achieved without undue treatment burden should guide the antihypertensive medication titration, as stopping medications after the goal is reached may lead to combined micro- and macrovascular complications [29].

Tight targets of systolic blood pressure (SBP) less than $120 \mathrm{mmHg}$ in 9361 patients aged at least 50 years old with high risk for CV events but without diabetes and with an SBP of at least $130 \mathrm{mmHg}$ have shown benefits in SPRINT [30]. On the other hand, in the ACCORD BP trial [31], 4733 patients with type 2 diabetes, average age 62 years, randomly assigned to intensive therapy, targeting an SBP less than $120 \mathrm{mmHg}$, or standard therapy, targeting an SBP less than $140 \mathrm{mmHg}$, significantly reduced only stroke but not mortality or $\mathrm{CV}$ outcomes. The fact that treatment of hypertension helps patients with diabetes more than those who do not have diabetes in various trials, tempts us to use SPRINT data in patients with diabetes. One recent (2016) systematic review and meta-analysis [32] suggests that reducing SBP to less than $140 \mathrm{mmHg}$ may be harmful in patients with diabetes. Relying on the ACCORD-BP trial, the JNC-8 [20] gave recommendations for less than 140/90, which was also accepted by others like ASH [27], AHA [26], and ADA [4].

The "J-shaped" phenomenon (paradoxical increase in morbidity and mortality associated with an excessive reduction in BP), which created controversy, was relaunched by the fact that the excess mortality is not due to low BP per se, but due to other factors (previous stroke, ischemic heart disease, or heart failure) [33]. In this study, BP reduction to under $120 \mathrm{mmHg}$ had no adverse outcomes. However, further lowering of BP needs confirmation in patients with diabetes from future trials, and we await to solve this major target controversy in the future in this subset of hypertension in patients with diabetes.

\section{Non-Pharmacological Interventions}

Salt restriction, weight loss, avoiding smoking, increasing activity, and decreasing alcohol intake may all play a part in the non-pharmacological management of hypertension in 
diabetes [4]. Counseling is important to enable the patient to understand the necessity of prescribed drugs and to reduce non-compliance and clinic non-attendance, which also form potential management problems, affecting mortality [34]. Since the "pill and bill" burden affects both the individual and the family, it is important to implement family therapy, to encourage better patient care and comfort, and thus better control of the disease and its complications [35]. It helps in relieving the stress of the disease, the protection of elderly hypertensives [36], and prevention of hypertension and its complications by educating caregivers in the family, especially the educated youth [37].

Home monitoring of blood pressure (HMBP) may be advantageous in control, compliance, adherence, and response to drugs. Ambulatory blood pressure monitoring (ABPM) is helpful in difficult cases, where there are differences in office and home readings, masked hypertension, and compliance issues. De-stressing strategies such as identifying stimuli and coping mechanisms are also adjuvants in hypertension treatment [38].

\section{Pharmacological Interventions}

Table 2 provides the various lines of drugs used in patients with diabetes and hypertension (complicated hypertension). Table 3 summarizes the metabolic profiles of the main antihypertensive drugs including changes in glucose and lipid profile.

\section{Antihypertensive Drugs}

1. RAAS blockers [ACEI (angiotensin converting enzyme inhibitors) and ARBs (angiotensin receptor blockers)]:

ACEI/ARBs remain the mainstay in the treatment of hypertension in a diabetes patient. They are not only beneficial in the prevention of new onset diabetes but also for albuminuria [4]. They protect kidneys by reducing efferent glomerular arteriolar tone and inhibit mesangial growth factors. ARBs are equally efficacious, with fewer side effects, although in real-world settings may be better than ACEI in stroke prevention
Table 2 Summary of drugs used in patients with diabetes and hypertension $[4,11]$

\begin{tabular}{|c|c|}
\hline Drug line & Drug class \\
\hline First-line drugs & $\mathrm{ACE} / \mathrm{ARB}$ \\
\hline \multirow{2}{*}{$\begin{array}{l}\text { Second-line } \\
\text { drugs }\end{array}$} & CCB (non-dihydropyridine) \\
\hline & Alphal blockers \\
\hline \multirow[t]{2}{*}{ Third-line drugs } & Thiazides \\
\hline & Beta blockers \\
\hline Fourth-line drugs & Centrally acting drugs and vasodilators \\
\hline
\end{tabular}

$A C E I$ angiotensin converting enzyme inhibitor, $A R B$ angiotensin receptor blocker, $C C B$ calcium channel blocker

Table 3 Metabolic profiles of different antihypertensive drugs [11]

\begin{tabular}{|c|c|c|c|}
\hline $\begin{array}{l}\text { Drug } \\
\text { class }\end{array}$ & $\begin{array}{l}\text { Effect on } \\
\text { glucose }\end{array}$ & $\begin{array}{l}\text { Effect } \\
\text { on } \\
\text { lipids }\end{array}$ & Comments \\
\hline Thiazides & Raise & $\begin{array}{l}\text { Raise } \\
\text { LDL } \\
\text { Lower } \\
\text { HDL }\end{array}$ & - \\
\hline $\begin{array}{l}\text { Beta } \\
\text { blockers }\end{array}$ & $\begin{array}{l}\text { (Raise) } \\
\text { glucose }\end{array}$ & $\begin{array}{l}\text { Raise } \\
\text { TG }\end{array}$ & $\begin{array}{l}\text { Decrease awareness of } \\
\text { hypoglycemia }\end{array}$ \\
\hline $\mathrm{CCB}$ & Neutral & Neutral & $\begin{array}{l}\text { Dihydropyridines may } \\
\text { increase proteinuria }\end{array}$ \\
\hline $\mathrm{ACE}$ & Neutral & Neutral & $\begin{array}{l}\text { Specific renoprotective } \\
\text { effect }\end{array}$ \\
\hline $\begin{array}{l}\text { Alpha } \\
\text { blockers }\end{array}$ & Neutral & $\begin{array}{l}\text { Raise } \\
\text { HDL } \\
\text { Lower } \\
\text { LDL }\end{array}$ & - \\
\hline
\end{tabular}

$A C E I$ angiotensin converting enzyme inhibitor, $C C B$ calcium channel blocker, $L D L$ low-density lipoprotein, $H D L$ high-density lipoprotein, $T G$ triglyceride

[39]. On the basis of evidence from ALTITUDE and ONTARGET, the combined use of ACEI/ARB is discouraged [40]. 
RAAS blockers have benefits beyond BP lowering [41], and the drug azilsartan, the newest addition to the sartan family, provides superior reduction of BP compared to olmesartan and telmisartan [42].

2. Diuretics [16]:

Chlorthalidone and indapamide are the two most frequently used diuretics in trials for the treatment of hypertension in diabetes. Their role in preventing heart failure in patients in ALLHAT makes them an important class in this group. They may be used as first-line or as add-on treatment. Concerns are monitoring of electrolytes and glucose.

3. Calcium channel blockers (CCBs) [4]:

CCBs may be used as first-line treatment for hypertension in elderly patients with diabetes and isolated systolic hypertension. They may also be used in patients with intolerance to RAAS blockers. They may help in preventing stroke, but have lower efficacy than RAAS blockers.

4. Beta blockers (BB):

This class of antihypertensives is used in diabetes patients with heart failure, ischemic heart disease, or tachycardia. Apart from these indications, BB are infrequently prescribed for diabetes patients. Concerns are masking hypoglycemia, impairing insulin sensitivity, weight gain, and deranged lipids $[4,43]$.

5. Alpha blockers:

These are used as third- or fourth-line agents, especially with prostate hyperplasia. They have less efficacy for stroke prevention and heart failure compared to other classes $[16,44]$.

6. Aldosterone antagonists [45]:

Used in hypertension in diabetes, e.g., spironolactone, effective in low doses, and more effective when serum potassium is less than $4.5 \mathrm{mmol} / \mathrm{L}$. Reduce albuminuria in diabetes patients, and renoprotection is independent of systemic hemodynamic alterations. Concerns are type 4 renal tubular acidosis, hyperkalemia, impotence, and gynecomastia. Finerenone is a newer nonsteroidal antimineralocorticoid with a lesser side effect profile [46].
7. Combination of antihypertensives [4]: Initiate combination therapy if not at goal or if initial BP is greater than $160 / 100$. Since BP in many patients with hypertension and diabetes is uncontrolled, CCB/diuretics are used as an add-on to therapy. Combining ACEI/ARB with CCB may offer better renoprotection and reduced ankle edema. Patients with volume overload or obesity do well on ACEI/ARB and diuretic combination. Patients uncontrolled on either may benefit from the triple combination of ACEI/ARB plus CCB plus diuretic. Effective combinations may be with alpha blockers and beta blockers in cases of prostatic hyperplasia and heart failure, respectively. Some patients whose BP remains uncontrolled, or with resistant hypertension, may need the further addition of aldosterone antagonists [44].

\section{Antidiabetic Drugs as Antihypertensives}

1. SGLT2i (sodium glucose cotransporter-2 inhibitors) [47]:

SGLT2i are novel antidiabetic drugs with antihypertensive properties. Canagliflozin, dapagliflozin, and empagliflozin all have BP-reducing properties. They reduce SBP/ DBP by $3-5 / 2-3 \mathrm{mmHg}$, respectively. The mechanisms are diuresis, nephron remodeling, reduced arterial stiffness, and weight loss. Reducing the doses of diuretics or other antihypertensive drugs is essential. This class of drugs is effective in patients with high glucose, BP, and weight $[48,49]$.

2. Incretins:

(a) GLP1-RA (glucagon-like peptide-1 receptor agonists):

Exenatide and liraglutide significantly reduced SBP and DBP by $1-5 \mathrm{mmHg}$ in a meta-analysis of 16 RCTs compared with antidiabetic drugs including insulin, glimepiride, and placebo for patients with T2DM [50].

Liraglutide [51] reduces SBP by nearly $1.5 \mathrm{mmHg}$, while the $1-\mathrm{mg}$ dose of semaglutide [52] reduces it by $2.6 \mathrm{mmHg} \quad(p<0.01)$. Both drugs 
reduce glucose and weight in diabetes patients. They have a mild reduction effect on BP, are cardioprotective, but should not be used as an alternative to antihypertensive drugs.

(b) DPP4i (dipeptidyl peptidase-4 inhibitors):

Sitagliptin has shown SBP reduction of 1-3 mmHg [53], while in other studies it reduced BP significantly $(p<0.01)$ without reducing body mass index [54] and also reduced office as well as home BP $(p<0.01)$ [55], thus confirming pleotropic effects of this class. Vildagliptin also was shown to lower central $\mathrm{BP}$, which is a glucose-independent beneficial effect of gliptins [56, 57]. DPP4i have been shown to have various effects on BP, and their overall effect may be considered as neutral. Though they have pressure-reducing effects, they should not be used as an alternative to antihypertensive drugs, at present.

\section{CONCLUSION}

Recent trends suggest to target treatment when BP is greater than 140/90. When achieved without undue treatment burden, BP targets of less than 130/80 $\mathrm{mmHg}$ may be appropriate for certain individuals with diabetes, like the young, with albuminuria, and/or those with hypertension and one or more additional atherosclerotic CV disease risk factors. Tighter targets of less than $140 / 90 \mathrm{mmHg}$ in patients $70-80$ years old and of less than 150/90 in the elderly (more than 80 years old) seem appropriate. Initiate combination therapy if not at goal or if initial BP is greater than 160/100.

ACEI/ARBs are the most effective drugs for treating hypertension in diabetes, in the absence of contraindications. Calcium antagonists or diuretics are probably appropriate as second-line agents. Newer antidiabetes medications such as SGLT2i have antihypertensive properties and may help in treatment decision-making and choices. Once the BP target is achieved, antihypertensive drugs should be continued in order to promote $\mathrm{CV}$ risk reduction. Future trials are needed to determine the appropriate BP targets for patients with diabetes.

\section{ACKNOWLEDGEMENTS}

No funding or sponsorship was received for this study or publication of this article. The article processing charges were funded by the author. The author meets the International Committee of Medical Journal Editors (ICMJE) criteria for authorship for this manuscript, takes responsibility for the integrity of the work as a whole, and has given final approval for the version to be published.

Disclosures. Altamash Shaikh has nothing to disclose.

Compliance with Ethics Guidelines. This article is based on previously conducted studies and does not involve any new studies of human or animal subjects performed by the author.

Open Access. This article is distributed under the terms of the Creative Commons Attribution-NonCommercial 4.0 International License (http://creativecommons.org/licenses/ by-nc/4.0/), which permits any noncommercial use, distribution, and reproduction in any medium, provided you give appropriate credit to the original author(s) and the source, provide a link to the Creative Commons license, and indicate if changes were made.

\section{REFERENCES}

1. Wang CCL, Reusch JEB. Diabetes and cardiovascular disease: changing the focus from glycemic control to improving long-term survival. Am J Cardiol. 2012;110:58B-68B. doi:10.1016/j.amjcard.2012.08. 036.

2. Cheung BM, Li C. Diabetes and hypertension: is there a common metabolic pathway? Curr Atheroscler Rep. 2012;14:160-6. doi:10.1007/s11883012-0227-2. 
3. Banach M, Aronow WS. Blood pressure J-curve: current concepts. Curr Hypertens Rep. 2012;14:556-66. doi:10.1007/s11906-012-0314-3.

4. American Diabetes Association. Standards of Medical care in diabetes - 2017. Diabetes Care. 2017;40(supp 1):1-142.

5. UK Prospective Diabetes Study Group. Tight blood pressure control and risk of macrovascular and microvascular complications in type 2 diabetes: UKPDS 38. BMJ. 1998;317(7160):703-13.

6. Dahlof B, Server PS, Poulter NR, et al. Prevention of cardiovas- cular events with an antihypertensive regimen of amlodipine adding perindopril as required versus atenolol adding bendroflumethiazide as required, in the Anglo-Scandinavian Cardiac Outcomes Trial-Blood Pressure Lowering Arm (ASCOT-BPLA): a multicentre randomised controlled trial. Lancet. 2005;366(9489):895-906.

7. Patel A, ADVANCE Collaborative Group, MacMahon $\mathrm{S}$, et al. Effects of a fixed combination of perindopril and indapamide on macrovascular and microvascular outcomes in patients with type 2 diabetes mellitus (the ADVANCE trial): a randomised controlled trial. Lancet. 2007;370(9590):829-40.

8. Sowers JR. Recommendations for special populations: diabetes mellitus and the metabolic syndrome. Am J Hypertens. 2003;16(11 Pt 2):41S-5S.

9. Mancia G. The association of hypertension and diabetes: prevalence, cardiovascular risk and protection by blood pressure reduction. Acta Diabetol. 2005;42(Suppl 1):S17-25.

10. Haffner SM, Lehto S, Rönnemaa T, Pyörölä K, Laakso M. Mortality from coronary heart disease in subjects with type 2 diabetes and in nondiabetic subjects with and without prior myocardial infarction. N Engl J Med. 1998;339:229-34.

11. Leese GP, Savage MW, Chattington PD, Vora JP. The diabetic patient with hypertension. Postgrad Med J. 1996;72:263-8.

12. Jesmin J, Rashid MS, Jamil H, et al. Gene regulatory network reveals oxidative stress as the underlying molecular mechanism of type 2 diabetes and hypertension. BMC Med Genom. 2010;3:45.

13. Fowler MJ. Microvascular and macrovascular complications of diabetes. Clini Diabetes. 2008;26(2):77-82.

14. Hansson L, Zanchetti A, Carruthers SG, et al. Effects of intensive blood-pressure lowering and low-dose aspirin in patients with hypertension: principal results of the Hypertension Optimal Treat- ment
(HOT) randomised trial. HOT Study Group. Lancet. 1998;351:1755-62.

15. SHEP Cooperative Research Group. Prevention of stroke by antihypertensive drug treatment in older persons with isolated systolic hypertension. Final results of the Systolic Hypertension in the Elderly Program (SHEP). JAMA. 1991;265(24):3255-64.

16. Barzilay JI, Davis BR, Bettencourt J, et al. Cardiovascular outcomes using doxazosin vs. chlorthalidone for the treatment of hypertension in older adults with and without glucose disorders: a report from the ALLHAT study. J Clin Hypertens (Greenwich). 2004;6(3):116-25.

17. Gaede P, Lund-Andersen H, Parving HH, Pedersen O. Effect of a multifactorial intervention on mortality in type 2 diabetes. $\mathrm{N}$ Engl $\mathrm{J}$ Med. 2008;358(6):580-91.

18. Krause T, Lovibond $\mathrm{K}$, Caulfield M, McCormack T, Williams B. Management of hypertension: summary of NICE guidance. BMJ. 2011;343:d4891.

19. ESH/ESC Task Force for the Management of Arterial Hypertension. Practice guidelines for the management of arterial hypertension of the European Society of Hypertension (ESH) and the European Society of Cardiology (ESC). J Hypertens. 2013;1(10):1925-38.

20. James PA, Oparil S, Carter BL, et al. 2014 Evidence-based guideline for the management of high blood pressure in adults: report from the panel members appointed to the Eighth Joint National Committee (JNC 8). JAMA. 2014;311(5):507-20.

21. Daskalopoulou SS, Rabi D, Zamke KB, CHEP for the Canadian Hypertension Education Program. The 2015 Canadian Hypertension Education Program recommendations for blood pressure measurement, diagnosis, assessment of risk, prevention, and treatment of hypertension. Can J Cardiol. 2015;31(5):549-69.

22. World Health Organization. A global brief on hypertension. Geneva: WHO; 2013.

23. International Diabetes Federation Clinical Guidelines Task Force. Global guideline for type 2 diabetes. Brussels: IDF; 2012.

24. Shimamoto K, Ando K, Fujita T, et al. The Japanese Society of Hypertension guidelines for the management of hypertension (JSH 2014). Hypertens Res. 2014;37(4):253-390.

25. Association of Physicians of India. Indian guidelines on hypertension (IGH) - III. 2013. J Assoc Physicians India. 2013;61(2 Suppl):6-36. 
26. Rosendorff CLD, Allison M, et al. AHA/ASH American Heart Association, American College of Cardiology, American Society of Hypertension. Treatment of hypertension in patients with coronary artery disease: a scientific statement from the American Heart Association, American College of Cardiology, and American Society of Hypertension. Circulation. 2015;131(19):e435-70.

27. Weber MA, Schiffrin S, White WB, et al. ASH/ISH clinical practice guidelines for the management of hypertension in the community a statement by the American Society of Hypertension and the International Society of Hypertension. J Hypertens. 2014;32(1):3-15.

28. PA, Sarafidis PA. Epidemiology of resistant hypertension. J Clin Hypertens (Greenwich, Conn). 2011;362:1575-85. doi:10.1056/NEJMoa1001286.

29. Hirakawa Y, Arima H, Webster R, et al. Risks associated with permanent discontinuation of blood pressure-lowering medications in patients with type 2 diabetes. J Hypertens. 2016;34(4):781-7.

30. SPRINT Research Group, Wright JT Jr, Williamson $\mathrm{JD}$, et al. A randomized trial of intensive versus standard blood-pressure control. N Engl J Med. 2015;373(22):2103-16.

31. ACCORD Study Group, Cushman WC, Evans GW, et al. Effects of intensive blood-pressure control in type 2 diabetes mellitus. $\mathrm{N}$ Engl $\mathrm{J}$ Med. 2010;362:1575-85. doi:10.1056/NEJMoa1001286.

32. Brunstrom M, Carlberg B. Effect of antihypertensive treatment at different blood pressure levels in patients with diabetes mellitus: systematic review and meta-analyses. BMJ. 2016;352:i717. doi:10. 1136/bmj.i717.

33. Adamsson Eryd S, Gudbjörnsdottir S, Manhem K, et al. Blood pressure and complications in individuals with type 2 diabetes and no previous cardiovascular disease: national population based cohort study. BMJ. 2016;354:i4070.

34. Currie CJ, et al. The impact of treatment noncompliance on mortality in people with type 2 diabetes. Diabetes Care. 2012;35:1279-84. doi:10.2337/dc111277.

35. Shaikh A, et al. Family therapy in diabetes mellitus. Indian Endocrinol Metab. 2013;17(Suppl 1):S292-4.

36. Liu J, Huang S, Yang X, Liu S, Cai L, Jiao J. Investigation and analysis on the implementation of family therapy for elderly patients with hypertension in community. J Resid Sci Technol. 2016;13(8). doi:10.12783/issn. 1544-8053/13/8/386.
37. Machado AP, et al. Educational strategies for the prevention of diabetes, hypertension, and obesity. Rev Assoc Med Bras. 2016;1992(62):800-8. doi:10. 1590/1806-9282.62.08.800.

38. Krause T, Lovibond $\mathrm{K}$, Caulfield M, McCormack T, Williams B. Management of hypertension: summary of NICE guidance. BMJ. 2011;343:4891.

39. Pai PY, Muo C, Sung FC, Ho HC, Lee YT. Angiotensin receptor blockers (ARB) outperform angiotensin-converting enzyme (ACE) inhibitors on ischemic stroke prevention in patients with hypertension and diabetes-a real-world population study in Taiwan. Int J Cardiol. 2016;215:114-9.

40. Jindal A, Naqvi SH, Waqar Salam M, Sowers JR. In: De Groot LJ et al, editor. Hypertension in diabetes. South Dartmouth: Endotext. 2000.

41. Kurtz TW, Kajiya T. Differential pharmacology and benefit/risk of azilsartan compared to other sartans. Vasc Health Risk Manag. 2012;8:133-43. doi:10. 2147/VHRM.S22595.

42. Phillips RA. Current and future treatment of hypertension in the SPRINT era. Methodist DeBakey Cardiovasc J. 2015;11:206-13. doi:10.14797/ mdcj-11-4-206.

43. Nilsson PM. Target blood pressure in diabetes patients with hypertension-what is the accumulated evidence in 2011? J Zhejiang Univ Sci B. 2011;12:611-23. doi:10.1631/jzus.B1101001.

44. The seventh report of the Joint National Committee on Prevention, Detection, Evaluation, and Treatment of High Blood Pressure. JNC 7. NIH Publication, No. 04-5230. 2004.

45. Unger T, Paulis L, Sica DA. Therapeutic perspectives in hypertension: novel means for renin-angiotensin-aldosterone system modulation and emerging device-based approaches. Eur Heart J. 2011;32:2739-47. doi:10.1093/eurheartj/ehr253.

46. Bakris G, Agarwal R, Chan JC, et al. Effect of finerenone on albuminuria in patients with diabetic nephropathy: a randomized clinical trial. JAMA. 2015;314(9):884-94.

47. Kalra S. Sodium-glucose cotransporter 2 (SGLT2) inhibitors and cardiovascular disease: a systematic review. Cardiol Ther. 2016;5:161-8. doi:10.1007/ s40119-016-0069-z.

48. Wilding JP, Charpentier G, Hollander P, et al. Efficacy and safety of canagliflozin in patients with type 2 diabetes mellitus inadequately controlled with metformin and sulphonylurea: a randomised trial. Int J Clin Pract. 2013;67(12):1267-82. 
49. Hach T, Gerich J, Salsali A, Kim G, Hantel S, Woerle $\mathrm{HJ}$, et al. Empagliflozin improves glycemic parameters and cardiovascular risk factors in patients with type 2 diabetes (T2DM): pooled data from four pivotal phase III trials. Diabetol Stoffwechs. 2014;9:142.

50. Wang B, Zhong J, Lin H, et al. Blood pressure-lowering effects of GLP-1 receptor agonists exenatide and liraglutide: a meta-analysis of clinical trials. Diabetes Obes Metab. 2013;15(8):737-49. doi:10. 1111/dom.12085.

51. Marso SP, Daniel G, Brown-Frandsen K, et al. Liraglutide and cardiovascular Outcomes in type 2 diabetes. N Engl J Med. 2016;375(4):311-22.

52. Marso SP, Bain SC, Consoli A, et al. Semaglutide and cardiovascular outcomes in patients with type 2 diabetes. NEJM. 2016;375:1834-44.

53. Mistry GC, Maes AL, Lasseter KC, et al. Effect of sitagliptin, a dipeptidyl peptidase- 4 inhibitor, on blood pressure in nondiabetic patients with mild to moderate hypertension. J Clin Pharmacol. 2008;48(5):592-8.
54. Ogawa $\mathrm{S}$, et al. Sitagliptin, a dipeptidyl peptidase-4 inhibitor, decreases systolic blood pressure in Japanese hypertensive patients with type 2 diabetes. Tohoku J Exp Med. 2011;223:133-5. doi:10.1620/ tjem.223.133.

55. Yuasa S, Sato K, Furuki T, et al. Primary care-based investigation of the effect of sitagliptin on blood pressure in hypertensive patients with type 2 diabetes. J Clin Med Res. doi:10.14740/jocmr2820w.

56. Cosenso-Martin LN, Giollo-Junior LT, Vilela-Martin JF. DPP-4 inhibitor reduces central blood pressure in a diabetic and hypertensive patient: a case report. Medicine. 2015;94:e1068. doi:10.1097/md. 0000000000001068 .

57. Marney AKS, Byrne L, Brown NJ. Interactive hemodynamic effects of dipeptidyl peptidase-IV inhibition and angiotensin-converting enzyme inhibition in humans. Hypertension. 2010;56(4):728-33. 